\title{
Letters
}

Website: bmj.com

Email: letters@bmj.com

\section{Road traffic injuries are a global public health problem}

EDITOR-Road traffic crashes and their sequelae are a scourge in all societies, both developed and developing. Each year over a million people are killed in road traffic collisions worldwide and some 10 million people are injured or disabled by these events, ${ }^{1}$ predominantly in low and middle income countries. ${ }^{2}$

Despite what is known about road traffic crashes and their health consequences, policymakers worldwide show little awareness of their contribution to the burden of disease; consequently they are neglected in service and policy. At the same time there has been limited funding, particularly in low and middle income countries, for traffic related research ${ }^{3}$ even though these injuries drain developing economies of 1-2\% of gross domestic product (about $\$ 100$ bn) each year, or twice the total development aid received worldwide by developing countries.

The critical issue is that road traffic injuries can be prevented. Many effective strategies have been identified in developed countries, but since the type of traffic injuries in developing countries differ greatly from those in developed countries, the prevention strategies, technologies, and policies cannot

Advice to authors
We prefer to receive all responses electronically,
sent directly to our website. Processing your letter
will be delayed unless it arrives in an electronic
form.
We are now posting all direct submissions to
our website within 24 hours of receipt and our
intention is to post all other electronic
submissions there as well. All responses will be
eligible for publication in the paper journal.
Responses should be under 400 words and
relate to articles published in the preceding
month. They should include 55 references, in the
Vancouver style, including one to the BMJ article
to which they relate. We welcome illustrations.
Please supply each author's current
appointment and full address, and a phone or
fax number or email address for the
corresponding author. We ask authors to declare
any competing interest. Please send a stamped
addressed envelope if you would like to know
whether your letter has been accepted or rejected.
Letters will be edited and may be shortened.
bmj.com
letters@bmj.com

\section{Advice to authors} will be delayed unless it arrives in an electronic We are now posting all direct submissions to We wite within 24 hours of receipt and our igible for publication in the paper journal.

Responses should be under 400 words and which they relate. We welcome illustrations. fax number or email address for the corresponding author. We ask authors to declare addressed envelope if you would like to know hether your letter has been accepted or rejected. letters@bmj.com simply be exported. They require specific testing and appropriate modification to ensure their effectiveness in developing societies.

The World Health Organization, as the lead coordinating agency for international public health, is guiding a science based programme of activities in the prevention of road traffic injury. In 2001 its department of injuries and violence prevention, together with partners, developed a multidisciplinary five year global strategy for this (www.who.int/violence_injury_prevention/ index.html). This strategy takes into consideration competing needs and expectations, and limited resources in many countries, and addresses long term sustainable goals.

The Global Forum for Health Research and the WHO are supporting an initiative to promote appropriate research in Africa, Asia, and Latin America (see www. globalforumhealth.org/pages/index.asp).

This North-South collaborative effort is embarking on an ambitious research agenda for the prevention of road traffic injuries. Complementarily, another initiative, led by the Harvard Center for Population and Development Studies and cosponsored by the WHO, addresses the problem of health equity and road traffic injuries. An alliance of partners will help 10 developing countries to develop appropriate policies and interventions over five years.

Dedicating an issue of the $B M J$ to road traffic injuries is a welcome step in the acknowledgement of this global public health problem. It is also a call for partners around the world to confront the growing epidemic and save lives.

Margie Peden acting team leader

Unintentional Injuries Prevention, Department of Injuries and Violence Prevention, World Health Organization, CH1211 Geneva 27, Switzerland pedenm@who.ch

Adnan Hyder assistant research professor Department of International Health, Bloomberg School of Public Health, Johns Hopkins University, Maryland, MD 21205, USA

1 Murray CJL, Lopez AD. Global health statistics: a compendium of incidence, prevalence and mortality estimates fo over 200 conditions. Harvard School of Public Health, Boston: Harvard University Press, 1996

2 Krug E, ed. A leading cause of the global burden of disease. Geneva: World Health Organization, 1999.

3 Ad Hoc Committee on Health Research Relating to Future Intervention Options. Investing in health research and development. Geneva: World Health Organization, 1996. (Document TDR/gen/96.1.)

4 World Bank. Investing in health: world development report 1993. London: Oxford University Press, 1993.

\section{Increasing visibility of speed cameras might increase deaths and injuries on roads}

EDITOR-In December 2001 the government announced changes to the colour and positioning of speed cameras. ${ }^{1}$ But what will the effect be on deaths and injuries caused by road traffic collisions related to speed? And where is the evidence for this change in policy?

Interventions to control speed seek to reduce both the likelihood and the severity of a collision. The setting of appropriate speed limits is a major strand of this preventive action, and speed cameras are one of the main methods of enforcing these. The effect of speed cameras on road traffic collisions is well documented. A study in London showed that deaths fell threefold, and a trial in eight police force areas saw a reduction in deaths and injury after the introduction of cameras. $^{23}$

Speed cameras will now be painted yellow and must be visible from a distance of 60 metres (66 yards) on roads with a speed limit of up to $40 \mathrm{mph}(64 \mathrm{~km} / \mathrm{h})$ and 100 metres (109 yards) on roads with a speed limit above that (figure). Police forces will also be forbidden from erecting warning signs on roads where there are no cameras. ${ }^{1}$

These measures seem designed to placate the angry minority of motorists who believe that drivers should be warned about impending cameras, giving them the chance to slow down. But this view is not based on evidence of health benefits. Hidden cameras are associated with net falls in speeds, crashes, and casualties when compared with visible ones. ${ }^{4}$

Increasing the visibility of cameras and banning dummy warning signs removes the uncertainty of where cameras are located. But this uncertainty is one of the only means of discouraging widespread speeding. Has the government given up on its goal of tackling the culture of speeding? Speeds may drop in the 183 metres (200 yards) either side of a camera. But there will be no disincentive for drivers to keep within limits in areas free of cameras. Persistent speeders are the most likely to report driving slower in the presence of cameras but no differently or faster in other areas. ${ }^{5}$

The introduction of high visibility speed cameras is a mistake. We need evidence that they are more effective than hidden cameras. If they do not reduce collisions, deaths, and injuries more effectively they should not be introduced. Road safety policy should be 


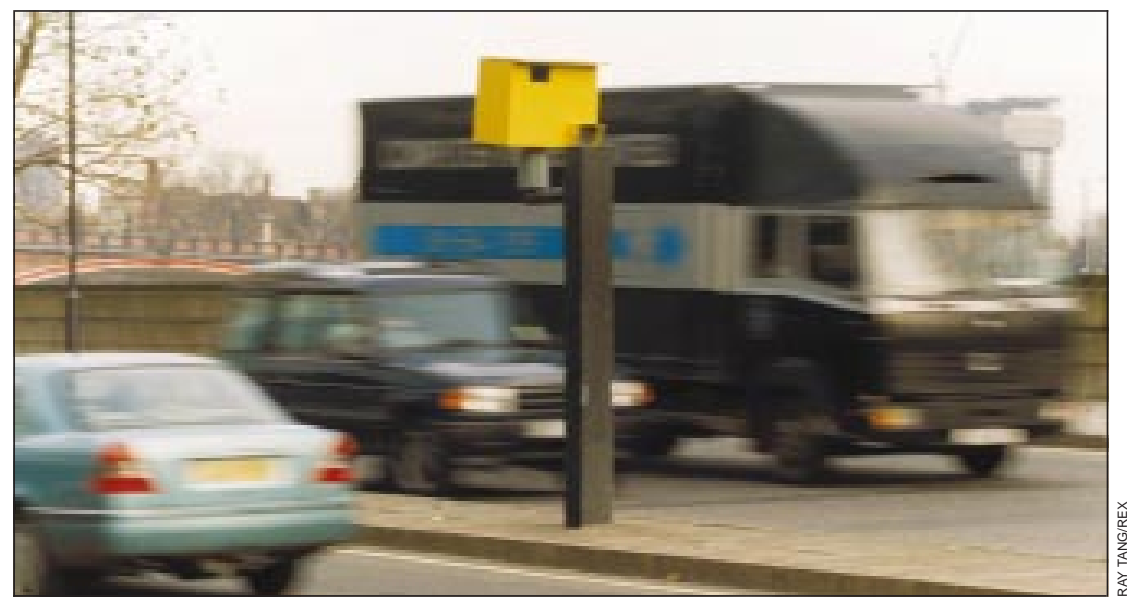

Will increased visibility of speed cameras have the desired effect of reducing deaths and injuries on the road?

based on evidence of health benefits and not on pressure from a vocal minority.

Paul Pilkington specialist in public health Avon Health Authority, Bristol BS2 8EE Paul.Pilkington@userm.avonhealth.swest.nhs.uk

1 Department of the Environment, Transport and the Regions. Spellar announces new camera visibility rules. London: DTLR, 2001. (DTLR news release 517.)

2 West R. The effect of speed cameras on injuries from road accidents. BMJ 1998;316:5-6.

3 Department for Transport, Local Government and the Regions. Cost recovery system for traffic safety cameras: first year report. London: DTLR, 2001

4 Keall MD, Povey LJ, Frith WJ. The relative effectiveness of a hidden versus a visible speed camera programme. Accid Anal Prev 2001;33:277-84.

5 Corbett C. Road traffic offending and the introduction of speed cameras in England: the first self-report survey. Accid Anal Prev 1995;27:345-54.

\section{System of renewal of driving licences for elderly people needs overhauling}

EDITOR-As a general practitioner, I believe that the guidance from the Driver and Vehicle Licensing Agency (DVLA) is unclear about when an elderly person should be advised or instructed to cease driving.

Conditions commoner in elderly people, but not unique to them, such as decreased visual acuity and myocardial infarction, have clear guidelines on how they restrict the licence to drive, but there is insufficient advice about slowed reaction times, decreased spatial awareness, or memory impairment. It may seem cruel to revoke the licence of elderly people when all they may do is drive to the post office or visit their spouse in hospital.

Although younger drivers are responsible for, and involved in, a greater number of serious road traffic crashes, many elderly people with developing dementia or general frailty should simply not be on the roads. I have known of people unable to look after themselves and yet still drive, albeit with navigational advice. Family members may plead with me to speak to an elderly relative about stopping driving, but this may be after such suggestions from them were met with resistance or indignation.

Currently, licence holders in the United Kingdom need to reapply for a driving licence on reaching the age of 70 and then every three years thereafter. This reapplication simply entails the completion of a form by the applicant with no medical examination or verification by the general practitioner or anyone else.

This self declaration that "no medical disability is present" is insufficient as what should be a comprehensive assessment of a driver and his or her abilities. There needs to be an overhaul of licence renewal in this country, with far greater independent medical assessment. Medical records need to be verified and cross checked, and the current system should be abandoned. Currently, the DVLA advises that "progressive loss of memory, impairment in concentration and reaction time with possible loss of confidence, suggest consideration be given to cease driving." This is far too arbitrary and is in urgent need of reassessment.

As one elderly patient remarked to me: "In this country if you can hold a pen you are allowed to keep driving."

David Carvel general practitioner

Biggar Medical Practice, Biggar ML12 6BE David.Carvel@biggar.lanpct.scot.nhs.uk

1 Drivers Medical Unit. At a glance guide to the current medical standards of fitness to drive. Swansea: DVLA, 2001.

\section{Controlled studies on reducing alcohol-impaired driving are} being registered

EDITOR-The Colorado Injury Control Research Center is developing a register of controlled studies that evaluate any intervention designed to prevent or reduce alcohol-impaired driving or its consequences. Examples include sobriety checkpoints, brief clinical interventions, and ignition interlock devices. We aim at including any controlled evaluation of a relevant intervention regardless of the outcomes measured.

The US Centers for Disease Control and Prevention has funded the register's development and dissemination. The studies identified will be included in the register of the Cochrane Injuries Review Group and will be available publicly through the Cochrane controlled trials register, part of the Cochrane Library.

The Colorado Injury Control Research Center is seeking expert and organisational input to identify relevant controlled studies that are unpublished, published only as internal reports, or otherwise not available through normal literature distribution channels. Any readers aware of such studies should please forward a complete citation and abstract, if available, to me.

Carolyn DiGuiseppi associate professor of preventive medicine

Department of Preventive Medicine and

Biometrics, B 119 University of Colorado Health

Sciences Center, Denver, CO 80210, USA

Carolyn.DiGuiseppi@uchsc.edu

\section{Tired surgical trainees}

\section{Junior doctors are not alone in getting tired: consultants do too}

EdITor-As one of the consultants who works with Jeffers and Keys, I confirm their statements about the intensity of their work and I echo their concerns. ${ }^{1}$

My unit is one of several in the United Kingdom that provides a consultant led, consultant delivered trauma service. This has arisen through a belief that involvement of senior staff leads to better outcomes for patients, coupled with official strictures limiting the extent of unsupervised trainee activity. As my unit is a tertiary referral centre for trauma, most emergency cases require lengthy and complex surgical intervention, mandating consultant input. The onerous hours worked by our trainees are usually shared by their supervising consultants.

Some important differences exist between the trainees and their consultant colleagues. There are no rest rooms for consultants, and nowhere to have even short periods of sleep or take a shower while on call. Regularly, after a sleepless night (or weekend) operating, we have to drive home before returning to the hospital at 8 am for the next day's work. This includes a morning trauma operating list, often followed by other NHS activity (for example, outpatient clinics)

The legal implications of the Gary Hart case $^{1}$ affect more than our trainees, and more than just the ability to drive home safely. Responsibility for the adverse surgical consequences of sleep deprivation will fall on the consultant in charge of the affected patient. Trusts must provide transport to and from home after a sleepless night at work, rest facilities, and safer working hours. This applies to all grades of staff working in labour intensive specialties.

Failure to provide legal and reasonable work patterns for doctors must result in unilateral action by the medical profession to ensure safety for ourselves and our patients. Inevitably, such unilateral action will be at the expense of elective practice, and therefore waiting lists. This may be the only (most effective?) card that we have left to 
play in the struggle to improve working conditions for those of us in the acute and hard pressed specialties.

Peter A Millner consultant orthopaedic and trauma surgeon

St James's University Hospital, Leeds LS9 7TF

Peter.Millner@leedsth.nhs.uk

1 Jeffers R, Keys L. Tired surgical trainees: unfit to drive but fit to operate? BMJ 2002;324:173. (19 January.)

Specialist registrars working in district general hospitals often travel considerable distances while tired

EDITOR-The Selby rail disaster has been covered extensively in the media. The jury ruled that the car driver had fallen asleep at the wheel after little sleep.

Calman training is region based. Specialist registrars are appointed to training posts that often include annual attachments in district general hospitals within a deanery, which can be geographically expansive. It is not exceptional for trainees to drive home from these hospitals-often over $80 \mathrm{~km}$ away-after busy nights on call without adequate sleep.

Trusts are currently tailoring junior doctor posts to be compliant with the new deal. This case has important implications for our professional responsibilities to the public both inside and outside the hospital grounds.

S A Townley specialist registrar in anaesthetics Bournemouth Hospital NHS Trust, Bournemouth BH7 7DW

Stephentownley@hotmail.com

1 Jeffers R, Keys L. Tired surgical trainees: unfit to drive but fit to operate? BMJ 2002;324:173. (19 January.)

\section{Sleep deprivation affects psychomotor} function

EDITOR-The deleterious effects of sleep deprivation on driving performance have long been suspected, and experimental studies have supported this. ${ }^{12}$ The duration of sleep deprivation required to cause an effect equivalent to that of a blood alcohol concentration of $80 \mathrm{mg} / 100 \mathrm{ml}$ (the legal driving limit) has been estimated at 21 hours. ${ }^{3}$

The imposition of a five year custodial sentence on the driver found guilty of causing death by dangerous driving in the Selby train disaster marks the law's recognition of this equivalence. In sentencing, Mr Justice Mackay stated: "In my view to take to the road in this condition is in moral terms little different than driving when one's judgment to drive is impaired by drink."

In the past it may have been more excusable to permit fatigued doctors to operate under conditions of impaired performance. I believe that this verdict and statement show an increasing intolerance of this situation by the courts and that this has further implications for the changing working patterns of doctors and those who manage them.

Mark Williams specialist registrar in anaesthesia Southampton General Hospital, Southampton SO16 6YD

mw5000@hotmail.com

1 Arnedt JT, Wilde GJ, Munt PW, MacLean AW. How do prolonged wakefulness and alcohol compare in the decre- ments they produce on a simulated driving task? Accid Ana Prev 2001;33:337-44.

2 Fairclough SH, Graham R. Impairment of driving performance caused by sleep deprivation or alcohol: comparative study. Hum Factors 1999;41:118-28.

3 Lamond N, Dawson D. Quantifying the performance impairment associated with fatigue. J Sleep Res 1999;8: $255-62$

\section{Breast screening guidelines should be adapted in Down's syndrome}

EDIToR-Piachaud and Rohde underlined the importance of including women with learning disabilities in screening programmes because of their reported increase in mortality from cancer, although no case of breast cancer was detected in patients with Down's syndrome. ${ }^{1}$ Patja et al observed that in Finland breast cancer was nearly as frequent in people with intellectual disabilities as in the general population. ${ }^{2}$ In the subgroup of 1012 women with Down's syndrome no breast cancer was observed, although 3.9 cases were expected. ${ }^{2}$

We conducted a national epidemiological study on mortality in France over 24 years, which showed only five deaths from breast cancer in women with Down's syndrome (68.98 expected (Fisher test; $\mathrm{P}<0.00005)$ ). ${ }^{3} \mathrm{~A}$ study conducted in the United States found only one death when 11.65 were expected. ${ }^{4}$ In Denmark no breast cancer was found in women with Down's syndrome compared with the 7.32 expected. ${ }^{5}$

A review of the literature including our own study yields only nine cases of breast cancer in patients with Down's syndrome. This is amazingly few if we keep in mind that breast cancer is the most frequent malignan neoplasm in women and if we compare it with the hundreds of cases of leukaemia reported and treated in patients with Down's syndrome.

People with learning disabilities should benefit from screening for breast cancer jus like the general population. The study of Patja et al shows its necessity. ${ }^{2}$ For women with Down's syndrome the reported studies show that breast cancer is nearly 10 -fold less frequent than in the general population. Tissues from people with Down's syndrome are more vulnerable to ionising radiations and particularly $x$ rays.

As repeated mammography may have deleterious effects, the relevance of breast cancer screening in women with Down's syndrome as it is usually done in the general population every two years is called into question. If these women are not included in such programmes we as doctors will have to determine how to manage the medical surveillance of their breasts. Possible options include repeated clinical examinations by trained professionals, ultrasonography, and magnetic resonance imaging. No experimental data currently support these recommendations, which cannot yet be viewed as guidelines but should be seriously considered in view of the likely unfavourable ratio of risk to benefit in women with Down's syndrome. As other genetic conditions are likely to be associated with a risk of breast cancer that is different (increased or decreased) from that in the general population, we recommend that specific attention should be paid to women with particular genetic conditions.

Daniel Satgé chief

Laboratory of Pathology, Centre Hospitalier,

19000 Tulle, France

daniel.satge@ch-tulle.fr

Annie J Sasco chief

Unit of Epidemiology for Cancer Prevention,

International Agency for Research on Cancer, 69

372 Lyons Cedex 8, France

1 Piachaud J, Rohde J. Screening for breast cancer is necessary in patients with learning disability. $B M J$ 1998;316:1979-80.

2 Patja K, Eero P, Livanainen M. Cancer incidence among people with intellectual disability. J Intel Disabil Res 2001;45:300-7.

3 Satgé D, Sasco AJ, Pujol H, Réthoré M-O. Les cancers mammaires des femmes trisomiques 21. Bull Acad Ntle Med 2001:185:1979-80. 4 Scholl T, Stein Z, Hansen H. Leukemia and other cancers, anomalies and infections as causes of death in Down's syn-

5 Hasle H, Clemmensen IH, Mikkelsen M. Risks of leukaemia and solid tumours in individuals with Down's syndrome. Lancet 2000;355:165-9.

\section{Researching outcomes of educational interventions}

\section{Theory based evaluation is interim measure of implementation}

EDITOR-As I produced the first description of theory based evaluation, ${ }^{1}$ readers might imagine that I would welcome Prideaux's support for the approach. ${ }^{2}$ Alas, no.

The point of theory based evaluation is to see, firstly, to what extent the theory is being implemented and, secondly, if the predicted outcomes then follow. It is particularly useful as an interim measure of implementation when the outcomes cannot be measured until much later.

But most (if not all) theories in social science are only sets of persuasively stated hypotheses that provide a temporary source of guidance. In order to see if the hypotheses can become theories one must measure the extent to which the predicted outcomes are achieved. This requires randomised controlled trials. Even then the important point is to establish the direction and magnitude of the causal relation, not the theory. Many theories can often fit the same data.

To suggest that controlled trials would be unethical because some postgraduates "would be given no choice over the learning methods they will engage in" is to raise issues that surround the conduct of any clinical trial. It may certainly be the case that some hypotheses are difficult to test, but in that case they should not be called theories or be claimed to be a guide to practice.

C T Fitz-Gibbon professor

University of Durham, Durham DH1 1TA

Carol.Fitz-Gibbon@cem.dur.ac.uk

1 Fitz-Gibbon CT, Morris LL. Theory based evaluation. Evaluation Comment 1975;5:1-4.

2 Prideaux D. Researching the outcomes of educational interventions: a matter of design. BMJ 2002;324:126-7. (19 January.) 


\section{Initial formation of unbiased groups is most important issue in randomised controlled trials}

EdITOR-Prideaux is correct in his claim that, in general, educational researchers "sometime ago abandoned the supremacy of randomised trials." To some of us working in educational research this was an enormous folly. ${ }^{2}$ Many arguments asserting that randomised controlled trials are inappropriate for educational research in medicine are familiar. Prideaux and the researchers he quotes, Norman and Schmidt, ${ }^{3}$ seem to misunderstand the methodology of randomised controlled trials.

The most important issue in randomised controlled trial methodology is the initial formation of two or more unbiased groups. Robust randomised controlled trials do not have to rely on the maintenance of blind allocation. There are many instances of trials in health care, such as surgical trials, in which the patient, surgeons, and other healthcare professionals are unblinded to the patients' allocated group. One would not advocate abandoning randomised trials of surgical treatments because the participants cannot be blinded.

The argument that a randomised controlled trial will not control for the myriad of factors associated with an educational intervention is misleading. If the randomisation procedure is undertaken adequately the factors not associated with the intervention should be evenly balanced. Other factors associated with the intervention will be an integral part of the educational package. For instance, part of any educational intervention may be the students' and teachers' enthusiasm for the method. If an educational method induces enthusiasm among its proponents and its students but fails to show a beneficial effect in a rigorous trial then it is time to reappraise that educational intervention, not the method of evaluating it.

Educational interventions are remarkably similar to health treatments in that when they work their effect sizes tend to be small. Albanese reports that the average effect size of medical education was less than 0.5 but also points out that many established healthcare treatments also produce such modest effects. ${ }^{4}$ To detect reliably an effect size of 0.5 (with an $80 \%$ power at a significance level of 5\%) requires about 126 students in total (63 in each group); Smits et al show no trial reaching that size. ${ }^{5}$ These authors are correct that problem based learning needs to be exposed to more, larger, and rigorous trials, not fewer. ${ }^{5}$

Carole J Torgerson research fellow

Department of Educational Studies, University of York, York YO10 5DD

cj3@york.ac.uk

1 Prideaux D. Researching the outcomes of educational interventions: a matter of design. BMJ 2002;324:126-7. (19 January.)

2 Torgerson CJ, Torgerson DJ. The need for randomised controlled trials in educational research. British Journal of Educational Studies 2001;49:316-28.

3 Norman GR, Schmidt HG. Effectiveness of problem-based learning curricula: theory, practice and paper darts. Med Educ 2000;34:721-28.
4 Albanese M. Problem-based learning: why curricula are likely to show little effect on knowledge and clinical skills. Med Educ 2000;34:729-38.

5 Smits PBA, Verbeek JHAM, de Buisonjé CD. Problem based learning in continuing medical education: a review of controlled evaluation studies. BMJ 2002;324:153-6. (19 January.)

\section{Author's reply}

EDITOR-It is interesting to note that both of these authors draw support for their arguments from the conduct of clinical trials. This is both helpful and unhelpful; it is unhelpful to attempt to explain away the problems of randomised control trials in educational research by stating that those in clinical research face similar issues.

The comparison with clinical trials is helpful in drawing attention to the ethics of research in medical education. ${ }^{1}$ Educational researchers using randomised control trials must seek the same level of informed consent for participation in trials as their clinical colleagues. But therein lie some major problems. It is not easy to recruit volunteers into a study in which they know that the choice of teaching and learning methods is taken out of their hands. The article by Smits et al focused on educational methods in continuing medical education. ${ }^{2}$ For some participants this would be a service for which they paid. How many adult learners would be prepared to pay for educational services in which they were not able to choose the learning process?

Blinding is essential in randomised control trials and is a more serious issue in educational research than in clinical trials. The effects will be small, for example, in trials of surgical interventions in which treatments are conducted by surgeons on their own patients. This is not the case for much educational research. Knowing the group to which they are allocated could substantially affect subjects' behaviours. At the very least Hawthorne effects may operate in experimental groups. How can researchers be sure that learners will follow the experimental protocols given to them, especially when the methods offered may not be their preferred style?

Randomised controlled trials could make an appreciable contribution to educational research, but in practice they rarely do because education is not readily constrained by experimental protocols. Where is the effort in educational research best expended? Should it be directed to designs that can capture the complexity of human interaction in education or to those whose protocols offer more restricted opportunities for meaningful research?

David Prideaux professor of medical education School of Medicine, Flinders University, Adelaide, South Australia 5001

David.Prideaux@flinders.edu.au

1 Morrison J, Prideaux D. Ethics approval for research in medical education. Med Educ 2001:35:1008.

Smits PBA, Verbeek JHAM, de Boisonjé CD. Problem based learning in continuing medical education: a review of controlled evaluation studies. BMJ 2009.324:153-6. of controlled evaluation studies. BMJ 2002;324:153-6. (19 January.)

\section{Standards are needed for quality of life clinical trials}

Editor-Jefferson and Demicheli say that health economics studies must come under a high level of scrutiny. ${ }^{1}$ There are parallels with the field of quality of life in clinical trials, and it is equally important that the $B M J$ considers developing guidelines concerning this for authors and peer reviewers.

An increasing number of clinical trials assessing quality of life are being published, and national bodies such as the National Institute for Clinical Excellence in the United Kingdom and the Food and Drug Administration in the United States increasingly value quality of life in the drug approval process. Yet evidence is growing that published clinical trials assessing quality of life have failed to meet good scientific standards of reporting.

Recently revised CONSORT guidelines help with designing and reporting good clinical trials, but they fail to address the key issues of clinical trials assessing quality of life. Critical issues such as the selection of quality of life measures, minimal standards of psychometric validity, agreed standards of cultural validity, agreement of acceptable levels of missing data, and standardised methods of analysis and reporting are lacking.

Attempts have been made by some authors, ${ }^{45}$ but we are still some way from having internationally agreed standards. Several international groups, including the International Society of Pharmocecomics, the European Regulatory Issues on QoL Assessment (ERIQA) Group, the International Society for Quality of Life Research, and the Quality of Life Methods Group of the Cochrane Collaboration, are progressing towards guidelines. Until researchers and peer reviewers are working with the same scientific standards, however, some aspects of the criticism proposed by Jefferson and Demicheli could be equally pertinent for clinical trials assessing quality of life.

Pending the availability of other international standards, we would encourage the $B M J$ to produce minimal standards for quality of life in clinical trials.

Andrew Bottomley coordinator

Fabio Efficace Lady Grierson research fellow

EORTC Quality of Life Unit, European

Organisation for Research and Treatment of Cancer, EORTC Data Centre, 1200 Brussels, Belgium abo@eortc.be

Peter M Fayers professor

Department of Public Health, Aberdeen University Medical School, Aberdeen AB25 2ZD

1 Jefferson T, Demicheli V. Quality of economic evaluations in health care. BMJ 2002;324:313-4. (9 February.)

Sanders C, Egger M, Donovan J, Tallon D, Frankel Reporting on quality of life in randomised controlled trials: bibliographic study. BMJ 1998;317:1191-4.

3 Lee CW, Chi KN. The standard of reporting of health-related quality of life in clinical cancer trials. J Clin Epidemiol 2000;53:451-8.

4 Revicki DA, Osoba D, Fairclough D, Barofsky I, Berzon R, Leidy NK, et al. Recommendations on health-related quality of life research to support labeling and promotional claims in the United States. Qual Life Res 2000:9·887-900.

5 Fayers P, Machin D. Quality of life. Assessment, analysis and interpretation Chishester: Wiley, 2000 . 


\section{Adherence to peak flow monitoring}

Information provided by meters should be part of self management plan

EDITOR-Reddel et al found high rates of adherence to a peak flow monitoring regimen and attribute this to the use of electronic devices. ${ }^{1}$ But is this the entire answer?

The authors note that the electronic peak flow monitoring took place in the context of regular visits and titration of drugs according to the peak flow data. They comment that "the context in which monitoring is undertaken may influence adherence" and note the importance of the perceived usefulness of peak flow data in ensuring that patients use these devices.

Might it be the design of the intervention-with regular follow up, clear self management plans, and clear linking of peak flow readings with drug doses-rather than the electronic measuring devices themselves that accounted for the high levels of adherence? In the absence of a comparator group that used only traditional devices it is difficult to conclude confidently that the electronic nature, or any other feature, of the devices was the reason for the high adherence achieved.

Data from our recent study of the views of patients with asthma regarding decision making in treatment tend to support the conclusion that it is the perceived usefulness of the information provided that determines whether peak flow meters are used. In our sample of 230 patients, drawn from both primary and secondary care and with a range of severity of asthma, 110 reported having a peak flow meter. Of these, only 32 stated that they would use peak flow readings to adjust drug doses, with 73 stating that they would not do so. By contrast, 180 of the 230 patients reported using symptoms to guide their use of drugs.

The conclusion that we draw from these data, and, we believe, the important message from the paper, is that only if the information provided by peak flow meterswhether electronic or not-is relevant and part of a fully explained self management plan will patients use them.

Ann-Louise Caress lecturer in nursing acaress@fs2.nu.man.ac.uk

Karen Luker professor of nursing

Kinta Beaver research fellow

School of Nursing, Midwifery and Health Visiting, University of Manchester, Manchester M13 9PL

Ashley Woodcock professor of respiratory medicine North West Lung Centre, Wythenshawe Hospital, Manchester M23 9LT

1 Reddel HK, Toelle BG, Marks GB, Ware SI, Jenkins CR, Woolcock AJ. Analysis of adherence to peak flow monitoring when recording of data is electronic. $B M$ 2002;324:146-7. (19 January.)

\section{Authors' reply}

EDITOR-We were in fact extremely careful not to claim that the observed high adherence was solely attributable to use of electronic devices. It seemed likely that the study design, with visual display of peak flow data and their incorporation into self management plans, contributed to good adherence, and indeed we observed a white coat effect on adherence after appointments. But additional observations led us to believe that study design alone was insufficient to explain the high adherence.

Firstly, patients also had one paper diary task - to tick a box if peak flow was above a designated trigger point for identifying exacerbations. Adherence with this simple task was extremely poor (completion on most days was $44 \%$ of paper diaries and on no days was $39 \%$, and there was evidence of retrospective completion). This striking contrast with adherence with electronic monitoring suggested either lack of perceived usefulness of the task or reluctance to use paper diaries.

Secondly, subjects with uniformly high adherence to monitoring had a wide range of adherence to the study drug, measured covertly. These observations suggested that the study design characteristics were not sufficient in themselves to engender high adherence with study tasks and that the ease of use of the electronic diary was also important. This is confirmed by a randomised controlled study in which, even though monitoring was not apparently linked to self management plans, use of electronic devices resulted in high adherence and accuracy compared with paper based monitoring. ${ }^{1}$ Another study has shown that patients prefer electronic diaries to paper based monitoring.

Caress et al report that only a minority of surveyed patients would use peak flow data to adjust drug doses. This is not surprising, as patients are unlikely to do this unless prompted by healthcare professionals, who are unconvinced of the benefit of monitoring. ${ }^{3}$ The concept of "unwilling nonadherence," in which inconvenience and practical difficulties contribute to poor adherence, is also likely to influence whether practitioners choose to use peak flow data in managing asthma.

Until now practitioners' views have been influenced by paper based monitoring, with attendant difficulties of poor accuracy, low adherence, and cumbersome calculations. Studies are needed to re-evaluate the role of monitoring in asthma now that technology can facilitate both monitoring itself and the incorporation of the data by the practitioner into customised asthma management plans.

Helen K Reddel senior research fellow

hkr@mail.med.usyd.edu.au

Brett G Toelle research officer

Guy B Marks research leader

Christine R Jenkins research leader

Institute of Respiratory Medicine, PO Box M77, Camperdown, NSW 2050, Australia

1 Chowienczyk PJ, Parkin DH, Lawson CP, Cochrane GM Do asthmatic patients correctly record home spirometr measurements? BMJ 1994;309:1618.

2 Godschalk I, Brackel HJ, Peters JC, Bogaard JM. Assessment of accuracy and applicability of a portable electronic diary card spirometer for asthma treatment. Respir Med 1996;90:619-22.

Jones A, Pill R, Adams S. Qualitative study of views of health professionals and patients on guided self management plans for asthma. BMJ 2000;321:1507-10.
4 Rand C, Wise R. Adherence with asthma therapy in the management of asthma: review and clinical guidelines. In Szefler S, Leung D, eds. Severe asthma:pathogenesis and clin cal management. Marcel Dekker: New York, 1995:435-64.

\section{Immunity conferred by smallpox vaccine}

\section{How long does immunity last?}

EDITOR-I am disappointed that Beeching et al do not provide a reference for their statement that immunity conferred by smallpox vaccination fades after 10-20 years, or earlier in some people. ${ }^{1}$ After watching a recent BBC programme about smallpox ${ }^{2}$ I was curious to know whether the smallpox vaccination I had had in childhood would still protect me.

It has been remarkably difficult to find out. Information on the website of the Centers for Disease Control and Prevention says, "Most estimates suggest immunity from the vaccination lasts 3 to 5 years." On the other hand, the World Health Organization's website says, "Anyone who has been vaccinated against smallpox ... will have some level of protection. The vaccination may not still be fully effective, but it is likely to protect you from the worst effects of the disease."

There is little published work on the subject: a Medline search using the search string "smallpox AND immunity AND duration" returned only nine papers, and most of these were not relevant to the question. One of the papers found that immunity can last up to 50 years, ${ }^{5}$ which is in stark contrast to the information on the Centers for Disease Control and Prevention's website.

Instead of saying that immunity fades after 10-20 years, perhaps a more honest statement would be that the duration of immunity is unknown.

Adam Jacobs director

Dianthus Medical Limited, London SW19 3TZ ajacobs@dianthus.co.u

1 Beeching NJ, Dance DA, Miller AR, Spencer RC. Biological warfare and bioterrorism. BMJ 2002;324:336-9. (9 February.)

2 Tonks A. We all fall down: could smallpox return? $B M J$ 2002;324:370. (9 February.)

3 www.bt.cdc.gov/DocumentsApp

FAQSmallpox.asp?link $=2 \&$ spage $=$ bio $\#$ Q9

4 www.who.int/emc/diseases/smallpox/faqsmallpox.html\#I www.who.int/emc/diseases/smallpox/faqsmallpox.htmI\#I
had the vaccination when I was a child. Am I still had the vace

5 Demkowicz WE, Littaua RA, Wang J, Ennis FA. Human cytotoxic T-cell memory: long-lived responses to vaccinia virus. J Virol 1996;70:2627-31.

\section{Authors' reply}

Editor-Jacobs's letter gives us the opportunity to expand on our statement and to cite the references requested, as there was insufficient space for this in our review. Jacobs highlights the inadequacy of Medline searches when one is dealing with questions that need a historically based answer. He would have found recent correspondence in ProMED to be a more useful source of information (www.promedmail.org/). Hopkins reviewed early writings of Edwardes, which cited higher rates of smallpox in adults than in children during British 
epidemics in the mid-19th century, reflecting the waning of immunity after unboosted primary childhood vaccination. ${ }^{12}$

There is considerable evidence that revaccination improves the protection of populations. The Prussians introduced compulsory revaccination every seven years for their army in 1834. This policy resulted in fewer cases of smallpox and deaths in the Prussian army than in the civilian population of Germany or the French army (neither of these was revaccinated) during the Franco-Prussian war of the 1870 s. $^{3}$

In their definitive work on smallpox, which is available on line, Fenner et al tabulate two studies that provide more quantitative modern data. ${ }^{4}$ Hanna reviewed an outbreak of variola major in Liverpool in 1902-3, in which protection against death was substantial after childhood vaccination, even after 50 years. ${ }^{5}$ Mack reviewed 680 cases of variola major imported into Europe and Canada in the mid-20th century; case fatality was $52 \%$ in unvaccinated people, $1.4 \%$ in those vaccinated $0-10$ years before the exposure, and $11 \%$ in those vaccinated over 20 years before the exposure. ${ }^{6}$

Tudor and Strati give the risk of smallpox developing in exposed people according to the interval since vaccination, citing $1: 1000$ at 1 year after vaccination, $1: 200$ at 3 years, $1: 8$ at 10 years, and $1: 2$ at 20 years. ${ }^{7}$ Thus primary vaccination has a clear protective effect against death that lasts for many years. The risk of illness developing after exposure to smallpox 10-20 years after childhood vaccination, however, remains substantial, even if the severity and mortality are reduced. The risk of transmission to others also remains considerable if any illness develops in the index case despite prior vaccination.

We believe that these data support our statement that immunity fades after 10-20 years. In past practice many countries required evidence of revaccination every three years, and during the final stages of the World Health Organization's eradication programme field workers were revaccinated more frequently to provide them with the most solid protection possible.

Nicholas J Beeching senior lecturer in infectiou. diseases

Division of Tropical Medicine, Liverpool School of Tropical Medicine, Liverpool L3 50A

Nicholas.Beeching@rlbuh-tr.nwest.nhs.uk

David A B Dance director

Public Health Laboratory, Derriford Hospital, Plymouth PL6 8DH

Alastair R O Miller consultant physician

Worcestershire Acute Hospitals NHS Trust,

Kidderminster Hospital, Kidderminster DY11 6RJ

Robert C Spencer consultant microbiologist

Bristol Public Health Laboratory, Bristol Royal Infirmary, Bristol BS2 8HW

1 Hopkins DR. Princes and peasants. Smallpox in history. Chicago: University of Chicago, 1983.

2 Edwardes EJ. A century of vaccination: small-pox epidemics and small-pox mortality before and since vaccination came into use. $B M J$ 1902;ii:27-30.

3 Rolleston JD. The smallpox pandemic of 1870-1874. Proc $R$ Soc Med 1933:27:15-30.

4 Fenner F, Henderson DA, Arita I, Jezek Z, Ladnyi ID. Smallpox and its eradication Geneva: World Health Organization, pox and its eradication. Geneva: World Health Organization, Smallpoxeradication
5 Hanna W. Studies in small-pox and vaccination. Bristol: Wright, 1913

Mack TM. Smallpox in Europe, 1950-1971. J Infect Dis 1972;125:161-9.

7 Tudor V, Strati I. Smallpox cholera. Tunbridge Wells: Abacus Press, 1977.

\section{Over the counter cough medicines for acute cough}

The fact that people keep buying the medicines is itself evidence

EDITOR-Schroeder and Fahey are right to urge caution in interpreting the results of their systematic review on cough medicines, and their recommendation to change existing guidance on cough medicines in the United Kingdom is not justified. ${ }^{1}$

Their review considered a heterogeneous group of products that included many different active ingredients from several different drug classes. It is surely impossible to draw from this any meaningful conclusions about over the counter cough medicines as a whole. Many of the products and active ingredients in the reviewed trials are either not available at all in the United Kingdom (moguisteine, bromhexine), are only available on prescription (salbutamol, terfenadine), or are not indicated for the relief of cough (loratidine, terfenadine).

Only 15 trials were included in the review, and only one reported a power calculation. As the authors concede, it seems highly likely that many of the remainder did not include sufficient patients to detect a difference from placebo, should one exist. The predictable upshot of this is that the review showed no evidence of effect-not evidence of no effect, as many will have inferred.

All the review really shows is the lack of good quality research on over the counter cough medicines. This should not surprise anybody, as most of the active ingredients in these medicines are old enough to have lost patent protection, and there are more pressing items on the research agenda. Patients derive enough benefit from over the counter cough medicines to purchase them in the first place and to keep returning for more. This in itself is evidence, although not of the double blind, randomised, placebo controlled variety.

If current advice on cough medicines is changed to appease the evidence based medicine purists, patients with uncomplicated upper respiratory tract infection are likely to consult their doctor. Not only is this an unnecessary use of a scarce resource but it is also likely to increase the number of inappropriate prescriptions for antibiotics.

James Walmsley senior medical adviser james.walmsley@boots.co.uk Graham Marshall head of medical services Boots the Chemists, Nottingham NG90 1BS

1 Schroeder K, Fahey T. Systematic review of randomised controlled trials of over the counter cough medicines for acute cough in adults. BMJ 2002;324:329-31. (9 February.)

\section{Good quality research is needed}

EDITOR-We agree with the response by Walmsley and Marshall (letter above) to the article by Schroeder and Fahey. ${ }^{12}$ Absence of evidence is not evidence of absence.

The paper's conclusion that there was no convincing evidence that over the counter treatments were helpful in acute cough was correct; but the extrapolation, highlighted in This Week in the BMJ, that these remedies should therefore not be recommended for first line treatment for cough associated with upper respiratory tract infection, is false. Walmsley and Marshall argue convincingly that, given the paucity of good randomised controlled trials, other evidence (which is mainly positive) should be taken into consideration. These over the counter remedies should not be discarded unless there is good evidence that they do not work.

Schroeder and Fahey's paper was presumably written before publication of the paper by Pavesi et al, ${ }^{3}$ which showed that the standard over the counter dose $(30 \mathrm{mg})$ of dextromethorphan caused a significant improvement in four out of five objective measures of cough (12-17 \%, compared with placebo), based on a meta-analysis of 710 patients. Because of the high variability of responses a large population has to be studied.

We have recently coauthored an editorial on cough, which, while regretting the paucity of good studies on cough in respiratory tract infection, takes a more balanced approach to over the counter remedies than the $B M J$ does. ${ }^{4}$ Most of us do not seek clinical intervention for acute cough, yet annually over $£ 100 \mathrm{~m}$ is spent in the United Kingdom on over the counter cough medicines. What is required is funding for good quality research, not sensational extrapolation from inadequate data.

John Widdicombe emeritus professor of physiology, University of London

GKT School of Biomedical Sciences, Department of Human Physiology and Aerospace Medicine, London SE1 9RT JohnWiddicombeJ@aol.com

Alyn Morice professor of respiratory medicine Academic Department of Medicine, University of Hull, Castle Hill Hospital, Cottingham HU16 5JQ

\footnotetext{
1 Walmsley J, Marshall G. Review should not change existing UK guidance on cough medicines. Electronic response to: Systematic review of randomised controlled trials of ove the counter cough medicines for acute cough in adults. bmj.com $2002 \quad$ (bmj.com/cgi/eletters/324/7333 329\# 19970; accessed 24 April 2002)

2 Schroeder K, Fahey T. Systematic review of randomised controlled trials of over the counter cough medicines for acute cough in adults. BMJ 2002:324:329-31. (9 February.) 3 Pavesi L, Subburaj S, Porter-Shaw K. Application and valiPavesi L, Subburaj S, Porter-Shaw K. Application and validation of a computerized cough acquisition system for objective mon

4 Morice AH, Widdicombe J, Dicpinigaitis P, Groenke L. Understanding cough. Eur Respir J 2002;19:6-7.
}

\section{Gap exists between practice and research}

EDITOR-The paper by Schroeder and Fahey made me laugh out loud. ${ }^{1}$ Of course cough medicines don't work; but as a general practitioner I shall continue encouraging patients to use them, and I hope that NHS Direct will do the same. Why? Well, parents of children with viral infections causing a cough present to doctors for a variety of reasons. 
Firstly, they are concerned that their child has a serious illness, usually meningitis or a chest infection.

Secondly, they are generally tired after being up all night and want help-any help.

Thirdly, they feel helpless in the face of their child's suffering and want to be able to do something. So we give them things to do, while they wait for the viral illness to get better on its own. We suggest Calpol (which contains paracetamol), we talk importantly about encouraging fluid intake and keeping the child cool, we even issue detailed instructions about how to inhale decongestants, and we advise parents of children with a cough to talk to their pharmacist about cough medicines. We then give them instructions about what to do if the condition worsens or doesn't improve over a specified (usually arbitrary) period.

The object of the exercise? To make them feel that they understand what's wrong, can do something to help, and have a fallback plan if things don't get better. Evidence based medicine has much to offer, but please don't let us confuse pharmacological efficacy with the real world of managing human emotions alongside physical illness.

Kath Checkland general practitioner Marple Cottage Surgery, Marple, Stockport SK6 5BW

kath.checkland@dial.pipex.com

1 Schroeder K, Fahey T. Systematic review of randomised controlled trials of over the counter cough medicines for acute cough in adults. BMJ 2002;324:329-31. (9 February.)

\section{Playing video games seems to have few serious acute adverse effects on health}

EDITOR-Cleary et al's letter about handarm vibration syndrome in people who play computer games needs to be put into a general context. ${ }^{1}$ I have examined both the possible dangers and the potential benefits of playing video games, and the literature suggests that they can have positive health benefits for a large range of subgroups-for example, the rehabilitation of patients with stroke or who have received burns, and to reduce pain in children undergoing chemotherapy. ${ }^{23}$

Medical side effects of playing video games have been reported ${ }^{45}$ and include photosensitive epilepsy, head and eye strains, auditory hallucinations, enuresis, encopresis, wrist pain, neck pain, and repetitive strain injuries. The possible long term effects and the relation of playing video games to conditions such as obesity remain speculative. All the case studies showing negative consequences of playing were of children and adolescents who used video games excessively.

When all factors and variables are taken into account and the prevalence of play is considered there is little evidence of serious acute adverse effects from moderate play. Adverse effects are likely to be relatively minor and temporary, resolving spontaneously with decreased frequency of play, or to affect only a small subgroup of players. People who play excessively are the most at risk from developing health problems, although more research is needed. ${ }^{34}$

Mark D Griffiths reader in psychology

Psychology Division, Nottingham Trent University, Nottingham NG1 4BU

mark.griffiths@ntu.ac.uk

1 Cleary AG, McKendrick H, Sills JA. Hand-arm vibration syndrome may be associated with prolonged use of vibratsyndrome may be associated with prolonged use of vib ing computer games. BMJ 2002;324:301. (2 February.)
2 Griffiths MD. Video games and clinical practice: issues, uses 2 Griffiths MD. Video games and clinical practice: iss

and treatments. BrJ Clin Psychol 1997;36:639-41.
Griffiths MD. Video games: the good news. Education and

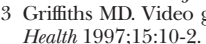

4 Griffiths MD, Wood RTA. Risk factors in adolescence: the case of gambling, video-game playing and the internet. Gambling Studies 2000;16:199-225.

5 Griffiths MD. Video games and children's behaviour. In Charlton T, David K, eds. Elusive links: television, video games cinema and children's behaviour. Gloucester: GCED/Park Publishers, 1997:66-93.

\section{Compliance is limited by opposing recommendations}

EDITOR-With regard to the comments by Keeley on community acquired pneumonia, I thought that some of the general practitioners who read the $B M J$ might be interested in our experience.

Tetracycline was used by our practice as a first line antibiotic for 8 years before last year. We were then visited by the medical advisers from the local health authority, who advised us that we were acting irrationally, contravening the General Medical Council's guidelines on good medical practice and wasting NHS funds. We were also advised that failure to change our prescribing would result in our not being reaccredited. Your readers may find this surprising as, of course, reaccreditation has not yet been introduced.

The health authority includes oxytetracycline as its antibiotic of choice, and it was strongly recommended that we switched to the use of this agent. The report from the local microbiology department knows of no difference whatsoever between tetracycline and oxytetracycline and, when using test strips on cultures, will use the terms interchangeably. In other words, the culture may have been found to be sensitive to oxytetracycline, but the lab report may state sensitivity to tetracycline.

A visit to the local hospital pharmacy also found that the staff use the drugs interchangeably, and, although the script may state oxytetracycline, the patient may well be given tetracycline and vice versa. A discussion with several local community pharmacists implied that this is not uncommon practice.

In 20 years of practice I have never been recommended by our local hospitals to prescribe tetracycline, although I am often recommended to prescribe other more expensive options and have received many complaints from my colleagues for the use of tetracycline. I believe that my compliance with recommendations is limited fundamentally by the bewildering array of diametrically opposed recommendations I am constantly receiving and the fact that there seems to be little practical logic to many of them. In conclusion, I would cite as my only reference a very old book that states that a man cannot serve two masters.

Tom Robinson general practitioner

Sully Surgery, 25 South Road, Sully, Penarth, Vale of Glamorgan CF64 5TG

1 Keeley D. Guidelines for managing community acquired pneumonia in adults. BMJ 2002;324:436-7. (23 February.)

\section{Making many small changes can result in quality improvement}

Editor-David Fillingham, the chief executive of the Modernisation Agency, comments that the staff in the NHS want to change but are too busy to do so. ${ }^{1}$ We would draw attention to that expert on management and quality improvement, A A Milne.

Predating the work of Deming, ${ }^{2}$ Berwick, ${ }^{3}$ and others, he stated simply:

Here is Pooh Bear, coming downstairs now, bump, bump, bump, on the back of his head, behind Christopher Robin. It is, as far as he knows, the only way of coming downstairs, but sometimes he feels that there really is another way, if only he could stop bumping for a moment and think of it. ${ }^{4}$

As Deming succinctly put it, if you have time to get it wrong you have time to get it right. Change is happening all the time, often without us realising. Every interaction in the NHS involves some change. When so much change seems imposed from above it is diffcult to see how, as an individual, we have any power. The key is to learn at every opportunity through taking an action, reflecting on what has happened, and then improving our practice on the basis of our results.

Although Pooh Bear cannot do anything but be pulled downstairs on his head, we can make small changes. Although these changes may seem insignificant at first, it is the constant process of learning and improving-the multiplicative effects of many small changes-that provide improvement breakthroughs. The results may not be statistically significant, but they may mean that we see fewer bruises.

Tim Wilson director, St Paul RCGP Ouality Unit Royal College of General Practitioners, London SW7 1PU

twilson@rcgp.org.uk

Sarah Fraser professor

Dinton, Buckinghamshire HP18 0AB

1 Smith J. The moderniser. BMJ 2001;323:1150. (17 November.

2 Deming WE. Out of the crisis. Boston: MIT Press, reprinted 2000

Berwick DM. Continuous improvement as an ideal in health care. N Engl J Med 1989;320:53-6.

4 Milne AA. Winnie the Pooh. Puffin, 1992. (First published in 1927.)

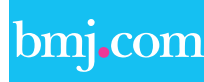

\section{Rapid responses}

Correspondence submitted electronically

is available on our website 